\title{
Intimate Partner Violence Leading to Femicide: A Case Report
}

\author{
Borukgama N, Hulathduwa SR* \\ Department of Forensic Medicine, Faculty of Medical Sciences, University of Sri Jayewardenepura, Gangodawila, \\ Sri Lanka
}

\begin{abstract}
Physical, psychological and sexual violence occurring between partners is termed intimate partner violence. It has medical, legal, social, cultural and economic adverse repercussions affecting not only the partners but also their children. It is a preventable social problem across the globe with varying prevalence. The most extreme forms result in 'intimate partner homicide'. Several risk factors have been identified for this condition, out of which the most important one being 'longstanding domestic violence'. When the victimized partner in intimate partner homicide is a female, the scenario is termed 'Femicide'. This case elaborates the death of a young female with two under-aged children caused by her drug addict husband probably by exerting sustained external pressure on the neck with an iron rod.
\end{abstract}

Keywords: Femicide, asphyxia, pneumothorax, drug abuse, strangulation

Received: 23 Nov 2021, Revised version accepted: 23 Dec 2021, Published: 31 Dec 2021. *Corresponding author: Hulathduwa SR, $\triangle$ sanjaya@sjp.ac.lk (D) https://orcid.org/ 0000-0002-4583-2703

Cite this article as: Borukgama N, Hulathduwa SR. Intimate Partner Violence Leading to Femicide: A Case Report. MedicoLegal Journal of Sri Lanka, 2021;9(2):30-33. DOI: http://doi.org/10.4038/mljsl.v9i2.7448

Copyright: @ 2019 with the Medico-legal Journal of Sri Lanka.

This is an open-access article distributed under the terms of the Creative Commons Attribution 4.0 International License, which permits unrestricted use, distribution, and reproduction in any medium provided the original author and source are credited.

\section{Introduction}

Intimate partner violence (IPV) is defined as physical violence, sexual violence, stalking or psychological harm by a current or former partner or spouse.[1] It is considered a serious, preventable public health problem worldwide. Intimate partner homicide (IPH) or fatal intimate partner violence is an extreme form of IPV.[2] Females are the commonest victims of IPH who are 4 to 5 times more vulnerable than males.[3] The word 'Femicide' is coined by some authors to describe the death of a woman following IPV. The major risk factor for IPH is identified as prior domestic violence.[3] Globally the rates of IPH have reduced over last two decades.[3]

Although the overall prevalence of IPV in Sri Lanka is about $25-30 \%$, the prevalence of the same in urban areas with poverty and compromised living standards (urban shanties) of the Western Province is much higher than the averaged values reaching approximately 60\%.[4] There are no official statistical data regarding intimate partner homicide in Sri Lanka. Sporadic cases are occasionally reported in the medico-legal literature and medicolegal specialists with an active practice for a considerably longer period of time come across this rarity during their career. The term 'Femicide' describes a homicide of a female due to the mere fact of being a female, conducted by any male, while the more specific term 'uxoricide' describes the killing of the wife or the girlfriend by her intimate partner.[5] According to several quantitative analyses conducted in different parts of the world, the commoner modes of intimate partner homicides include using firearms, causing sharp trauma and to a lesser degree, mechanical asphyxia by ligature strangulation or manual strangulation.[2,6]

This case describes the investigation of the death of a young female who succumbed to severe assaults by her husband.

\section{Case report}

A 30-year-old female, a mother of two children was living with her lawfully married husband who was a drug addict. She was found dead in a storage area adjacent to her house. The body of the deceased was found by her mother who lived in a neighbouring house. After hearing her daughter screaming she had gone to the victim's house within several minutes. There is a history of repeated episodes of intimate partner violence by the assailant husband prior to this event. They had a dispute on the day she was assaulted and murdered as witnessed by her mother. Husband later confessed that he had committed the murder of the victim by hitting the sides of her neck with an iron rod but denied strangulation or smothering.

The postmortem examination of the women was carried out subsequent to a magisterial inquest. The 
deceased was a small-built young female. There was an irregular abraded contusion of $10 \times 6 \mathrm{~cm}$ in dimensions placed over the anterior aspect of the root of the neck and superior part of the thorax more towards the left side. (Figure 1A). There were multiple linear abrasions over the left forearm (Figure 1B). Additionally, there were multiple grazed abrasions placed on the lateral aspect of the right thigh, on the left arm and on the posterior aspect of the right shoulder. Further, there were several irregular abrasions on the face. There were petechial haemorrhages on conjunctivae of both eyes, nasal bleeding and congestion above the neck of the body. There were no lip injuries or peri-oral injuries. No gagging material was found within the throat during the autopsy. There were no markings suggestive of a ligature mark around the neck or any tramline contusion elsewhere on the body.
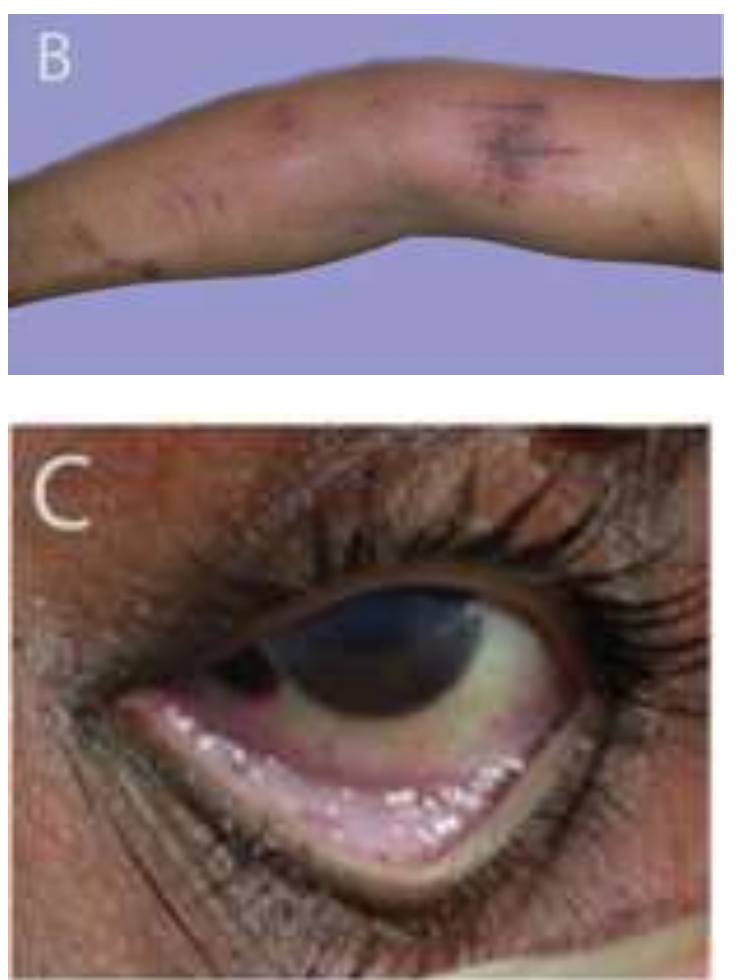

Figure 1: A-Irregular abrasion on the anterior aspect of the thorax and neck. B-Abrasions on the left forearm, C-Petechial haemorrhages and conjunctival haemorrhage in the left eye

Internal examination revealed extensive injuries to the front of the neck, face and chest. There was a displaced ante-mortem fracture of the body of the mandible on the right side. Ante-mortem fractures of bilateral greater horns of the hyoid bone and bilateral superior cornua of the thyroid cartilage were noted. Furthermore, bilateral first rib fractures and bilateral haemothorax of approximately $300 \mathrm{ml}$ on the right side and $400 \mathrm{ml}$ on the left side were noted. Additionally, extensive strap muscle contusions were observed. (Figure 2A) Notably, disruption of connective tissues surrounding the hollow viscera of the neck was noted, which usually results in increased mobility of the trachea and the oesophagus. Cervical spinal injuries or major vessel injuries of the neck were excluded. Musculoskeletal dissection of the posterior aspect of the body demonstrated a contusion over the inter-scapular area of the back of the chest. (Figure 2B).
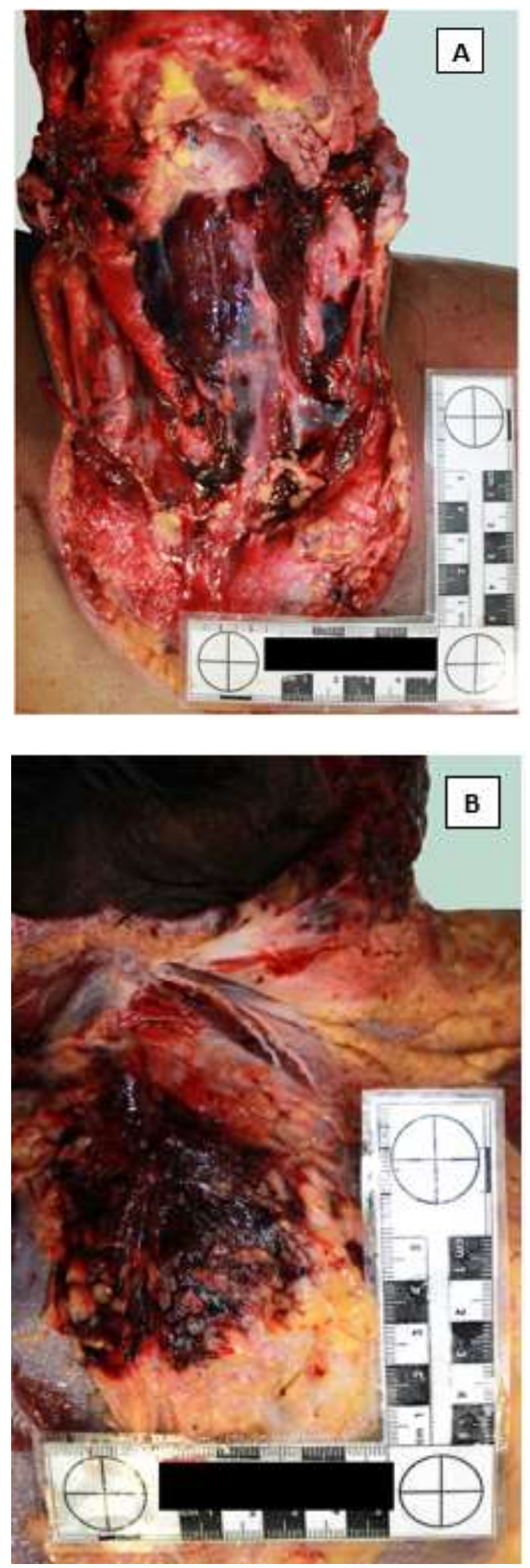

Figure 2: A-Dissection of the neck showing strap muscle contusions, B-Subcutaneous contusion on the inter-scapular 
Head injuries, thoracic or abdominal organ injuries were not noted during the macroscopic examination during autopsy. Additionally, there were no obvious organ pathology or anatomical abnormality suggestive of any natural disease condition. No evidence of poisoning was found during dissection. Samples were collected for routine toxicology and histopathology. Toxicology reports were negative.

\section{Discussion}

The major injuries noted on the body were confined to the neck, superior part of the thorax and lower part of the face. Several minor abrasions noted on the other parts of the body were mainly suggestive of defense injuries and injuries due to dragging on an irregular surface. All the injuries were compatible with those caused due to blunt force. Stabs, cuts, other forms of perforating injuries, burns and firearm injuries as well as previous tell-tale marks of such incidences were not found. Even though some injuries were compatible with the given history of assaulting with a heavy metal object, there were no obvious injuries such as gross cranio-cerebral injuries, cervical spinal injuries or severe internal organ damage that would have caused a rapid death. Furthermore, the abraded contusion on the anterior aspect of the chest was more suggestive of a friction abrasion resulted due to contact with a smooth broad surface than being caused due to impact with a metal pole. The contusion noted over the back of the chest was also suggestive of blunt force trauma. When above two injuries are considered collectively, with the internal findings of the neck; it is suggestive of fixation and compression of the neck, with the possible compression of body against ground by assailant while getting on to the upper chest from front as a plausible reconstruction of the event. The presence of classical signs of asphyxia such as petechial hemorrhages, overt hemorrhages (scleral hemorrhage, nasal bleeding) and facial congestion is, to a certain extent, non-specific in this case.

Yet, such features are suggestive of sustained obstruction of the venous drainage of the head.[7] There was no evidence suggestive of poisoning or aggravation of a pre-existing natural illness. Considering the above findings with the available history and circumstantial evidence, the cause of death could be formulated as 'fatal pressure on the neck'.

Deciding upon the exact method of asphyxia is difficult in this case due to the complexity of injuries as well as their non-specific nature. Manual strangulation and compression of the neck by the metal rod are possible modes though the presence of a component of traumatic asphyxia cannot be completely excluded. Burking is a method of homicide conducted by smothering combined with traumatic asphyxia exerted by the assailant's body- weight by getting onto the chest of the victim.[8] In this case, there were no injuries suggestive of smothering by hand, yet smothering cannot be completely excluded as it could occur without any injuries.

The probable operating mechanisms of death in this case could be considered as venous obstruction resulting in cerebral hypoxia as it could explain the occurrence of classical asphyxial signs. Vagal inhibition is another mechanism that could occur due to neck trauma, which can result in rapid death even without sustained compression, though it is unlikely in this case, as sudden cardiac arrest will result in a pale face rather than features of congestion and other established features of asphyxia.[7]

Intimate partner homicide (IPH) is the most extreme form of intimate partner violence. The greatest risk factor for IPH is the history of repeated IPV.[2,3] Many other risk factors have been identified contributing to IPV and IPH. Co-habitation, the increased age difference between the two partners and estrangement are found to have a relationship with the increased risk of uxoricide. $[9,10]$

Substance abuse and being under the influence of abusive substances at the time of the event are found to have a strong relationship with IPV and increased risk of IPH.[11] Intimate partner violence has many adverse impacts on the physical, mental and social wellbeing of the children. This comes in the most heinous form with intimate partner homicide as they lose one parent forever while the other parent may be incarcerated depriving the children of the support of both parents.

\section{Conclusions}

This case elaborates the death of a young female as a result of chronic intimate partner violence ending up as an intimate partner homicide which is a rare occurrence in the Sri Lankan setup. An asphyxial mode of homicide had been employed using a heavy elongated metal object to exert external pressure on the neck region.

\section{Disclosure statement}

Conflicts of interest: The authors declare that they have no conflicts of interest.

\section{Funding: None}

\section{References}

1. Breiding M, Basile KC, Smith SG, Black MC, Mahendra RR. Intimate partner violence surveillance: uniform definitions and recommended data elements. Version 2.0. 2015 [cited 2021 Aug 4]; Available from: https://stacks.cdc.gov/view/cdc/31292 
2. Adhia A, Kernic MA, Hemenway D, Vavilala MS, Rivara FP. Intimate partner homicide of adolescents. JAMA Pediatr. 2019;173(6):571-7.

3. Campbell JC, Glass N, Sharps PW, Laughon K, Bloom T. Intimate partner homicide: review and implications of research and policy: Review and implications of research and policy. Trauma Violence Abuse. 2007;8(3):246-69.

4. Guruge S, Jayasuriya-Illesinghe V, Gunawardena N, Perera J. Intimate partner violence in Sri Lanka: a scoping review. Ceylon Med J. 2015;60(4):133-8.

5. Home: Oxford English Dictionary [Internet]. Oed.com. [cited 2021 Aug 4]. Available from: https://www.oed.com/

6. Pereira AR, Vieira DN, Magalhães T. Fatal intimate partner violence against women in Portugal: a forensic medical national study. J Forensic Leg Med. 2013;20(8):1099-107.

7. Saukko PJ, Knight B. Knight's forensic pathology fourth edition [Internet]. 4th ed. London, England: Hodder Arnold; 2015. Available from: http://dx.doi.org/10.1201/b13266

8. Prasad D. Burking: A case report. J evol med dent sci. 2014;3(39):9959-63.

9. Shackelford TK, Mouzos J. Partner killing by men in cohabiting and marital relationships: a comparative, cross-national analysis of data from Australia and the United States: A comparative, cross-national analysis of data from Australia and the United States. J Interpers Violence. 2005;20(10):1310-24.

10. Wilson M, Daly M. Spousal homicide risk and estrangement. Violence Vict. 1993 Spring;8(1):3-16.

11. Vatnar SKB, Friestad C, Bjørkly S. A comparison of intimate partner homicide with intimate partner homicide-suicide: Evidence from a Norwegian national 22-year cohort. J Interpers Violence. 2019;886260519849656. 